\title{
Adenovirus-Mediated Gene Transfer of TGF- $\beta 1$ to the Renal Glomeruli Leads to Proteinuria
}

\author{
Ayesha Ghayur, ${ }^{*}$ Limin Liu, ${ }^{*}$ Martin Kolb, ${ }^{*}$ \\ Arun Chawla, ${ }^{\dagger}$ Shahid Lambe, ${ }^{\dagger}$ Anil Kapoor, ${ }^{\dagger}$ and \\ Peter J. Margetts* \\ From the Departments of Medicine* and Surgery, ${ }^{\dagger}$ McMaster \\ University, Hamilton, Ontario, Canada
}

The mechanism of proteinuria in many common kidney diseases involves glomerular hemodynamic effects and local expression of angiogenic, fibrogenic, and vasoactive factors. Transforming growth factor (TGF)- $\beta$ has been associated with many diseases involving proteinuria and renal fibrosis. TGF- $\beta$ has been shown to induce podocyte dedifferentiation in vitro, but its in vivo effects on the glomerular filtration barrier are not well described. In this study, we used an adenovirus vector to transfer active TGF- $\beta 1$ to the glomeruli of rat kidneys. Transient TGF- $\beta 1$ overexpression induced significant proteinuria, podocyte foot process effacement, nephrin down-regulation, and nephrinuria. The expression of synaptopodin was also significantly down-regulated by TGF- $\beta 1$. Increased glomerular expression of Snail, suggestive of an in vivo dedifferentiation process, was associated with a loss of podocyte epithelial markers. The expression of angiopoietin-1 and angiopoietin-2 was significantly increased in TGF- $\beta 1$-transfected glomeruli, and TGF- $\beta 1$ increased the expression of the angiopoietin receptor, Tie2, in podocyte cell culture. TGF- $\beta 1$ down-regulated nephrin and synaptopodin expression in podocytes in cell culture; this effect was reversed by the blockade of both angiopoietin and Tie2 activities. These findings suggest that locally produced TGF- $\beta 1$ can cause podocyte dedifferentiation marked by a loss of synaptopodin, nephrin, and foot process effacement, partly regulated by angiopoietins. This process represents a novel pathway that may explain proteinuria in a variety of common renal diseases. (Am J Pathol 2012, 180:940-951; DOI: 10.1016/j.ajpath.2011.11.023)

Proteinuria is a common finding in many kidney diseases, such as diabetes, hypertension, and chronic glomerulonephritis. Increased proteinuria is strongly associated with glomerulosclerosis, interstitial fibrosis, and progres- sion of chronic kidney disease. ${ }^{1}$ Proteinuria is related to a dysregulation in the glomerular filtration apparatus. This is a complex structure and includes the podocyte and associated slit diaphragm, basement membrane, and endothelium. Proteinuria has been associated with retraction of the podocyte foot processes, leading to effacement, disruption of the slit diaphragm, ${ }^{2}$ dedifferentiation, ${ }^{3}$ detachment, and apoptosis. ${ }^{4}$ Podocyte dedifferentiation has been described as an epithelial-to-mesenchymal transition (EMT)-like process by Li et al. ${ }^{3}$ Other mechanisms of proteinuria may include endothelial dysfunction ${ }^{5}$ and dysregulation of tubular protein reabsorption. ${ }^{6}$

Paracrine interaction between endothelium and podocytes is increasingly recognized as an important component of maintaining the glomerular filtration barrier. ${ }^{7}$ This interaction involves angiogenic factors, such as vascular endothelial growth factor (VEGF), ${ }^{8}$ angiopoietin (Ang) 1, and Ang2. ${ }^{5,9}$ Glomerular endothelial cells show evidence of dysfunction, such as swelling and loss of fenestrae, at an early stage of injury. ${ }^{10}$ They secrete transforming growth factor (TGF)- $\beta$ in response to VEGF stimulation ${ }^{11}$ and, in turn, exposure to TGF- $\beta$ increases endothelial permeability. $^{12}$

The appearance of nephrin, an integral slit diaphragm protein, in the urine is an early marker for podocyte injury and subsequent progression of kidney disease. ${ }^{13}$ Recent evidence suggests that the intracellular actin cytoskeleton and the associated protein synaptopodin have a role in maintaining foot process structure and preserving the glomerular filtration function. ${ }^{14}$

Progressive chronic renal disease is characterized by accumulation of extracellular matrix in both glomeruli and interstitium. The mechanism of progression of the injury from the glomerular to the tubulointerstitial compartment

Supported by the Kidney Foundation of Canada and St. Joseph's Healthcare, Hamilton, ON, Canada. P.J.M. and M.K. are Canadian Institutes of Health Research Clinician Scientists.

Accepted for publication November 11, 2011.

Preliminary data were presented as an abstract at the meeting of the American Society of Nephrology, 2007, Oct 31-Nov 5, San Francisco, CA

Address reprint requests to Peter J. Margetts, M.D., Ph.D., Department of Medicine, McMaster University, Division of Nephrology, St Joseph's Hospital, 50 Charlton Ave E, Hamilton, Ontario, Canada L8P 4A6. E-mail: margetts@mcmaster.ca. 
is not clear, but likely involves direct effects of proteinuria, filtered cytokines and growth factors, interstitial inflammation, and hypoxia. ${ }^{15}$ Local up-regulation of fibrogenic factors, such as TGF- $\beta$, plays a key role in progression of chronic kidney disease. ${ }^{16}$

Therefore, TGF- $\beta$ is involved in extracellular matrix accumulation, fibrosis, and progressive renal impairment, and plays a role in changes to the glomerular filtration barrier and induction of proteinuria. There is substantial clinical evidence to support this latter observation. Urinary TGF- $\beta$ correlates with the degree of proteinuria. ${ }^{17}$ Direct inhibition of TGF- $\beta$ in models of renal disease appears to reduce proteinuria. ${ }^{18,19}$ Proteinuria was described in two animal models of TGF- $\beta$ overexpression. ${ }^{20,21}$ In our study, we were interested in further examining the mechanism of TGF- $\beta$-induced proteinuria. We used an adenovirus to overexpress active TGF- $\beta 1$ in glomeruli of rats and found that we could induce significant proteinuria that was associated with podocyte dedifferentiation. An interaction between TGF- $\beta 1$ and angiopoietins in podocytes appears to be important in this effect.

\section{Materials and Methods}

\section{Animals}

All animal studies were performed according to Canadian Council on Animal Care Guidelines, and approval was received from the university animal research ethics board. Female Sprague-Dawley rats (weight, 200 to $250 \mathrm{~g}$; Harlan, Indianapolis, IN) were anesthetized with isoflurane (MTC Pharmaceuticals, Cambridge, ON, Canada). A midline incision was made, a PE10 catheter (Becton Dickinson, Mississauga, ON, Canada) was advanced from the abdominal aorta into the left renal artery, and the catheter was secured in place by a clamp. The left kidney was perfused with $1.5 \mathrm{~mL}$ of cold saline containing $5 \times 10^{9}$ plaque-forming units of an adenovirus expressing green fluorescent protein (AdGFP) or active TGF- $\beta 1$ (AdTGF- $\beta 1$ ). The adenovirus solution included $25 \mathrm{U}$ of heparin and was infused using a syringe pump (Razel Scientific, St Albans, VT). The left kidney was packed with ice-cold saline-soaked sterile gauze during infusion.

Animals receiving AdGFP or AdTGF- $\beta 1$ (seven animals per group per time point) were sacrificed after 7 and 28 days. Urine samples were obtained at days 4 , 7, 14, 21, and 28. After sacrifice, left and right kidney tissue was taken separately for histological, protein, and RNA analysis.

Four animals were treated with an adenovirus expressing $\beta$-galactosidase (AdLacZ) and were sacrificed at days 7 and 28 ( $n=2$ at each time point).

\section{Adenovirus}

Adenoviral vectors expressing GFP, $\beta$-galactosidase, and active TGF- $\beta 1$ were expanded, purified with $\mathrm{CsCl}$ gradient centrifugation, and plaque titered on 293 cells, as previously described. ${ }^{22} \mathrm{AdDL}$ is a null adenovirus and was used as a control for cell culture transfection.

\section{Histological Findings}

Formalin-fixed sections were stained for Masson's trichrome. Immunohistochemistry (IHC) was performed for $\alpha$-smooth muscle actin (SMA; Dako Corp, Carpentaria, CA) and synaptopodin (Progen Biotechnik, Heidelberg, Germany). Glomerular synaptopodin immunostaining was quantified using Northern eclipse software (Empix Imaging, Mississauga, ON, Canada).

Formalin-fixed sections were stained with antibodies against GFP (Santa Cruz Biotechnology, Santa Cruz, CA) with a secondary fluorescein isothiocyanate-labeled antirabbit antibody (Jackson Immunoresearch, Bar Harbor, $\mathrm{ME}$ ). Dual immunofluorescence was performed using $\alpha$-SMA (Dako Corp), CD34 (R\&D Systems, Minneapolis, $\mathrm{MN}$ ), or synaptopodin (Progen Biotechnik). Texas red secondary antibodies (Jackson Immunoresearch) were used.

Picrosirius red staining and quantification were performed as previously described. ${ }^{23}$ Staining for $\beta$-galactosidase was performed in animals infected with AdLacZ. Fresh tissue was fixed in $2 \%$ formaldehyde with $0.2 \%$ glutaraldehyde for 3 hours. Sections were stained with potassium ferrous cyanide, potassium ferric cyanide, and magnesium chloride (Sigma-Aldrich, Oakville, ON, Canada), with Triton X-100 and 5-bromo4-chloro-3-indolyl- $\beta$-D-galactopyranoside (Boehringer Mannheim, Indianapolis, IL).

\section{Electron Microscopy}

Kidney samples for electron microscopy were taken from formalin-fixed, paraffin-embedded blocks, then
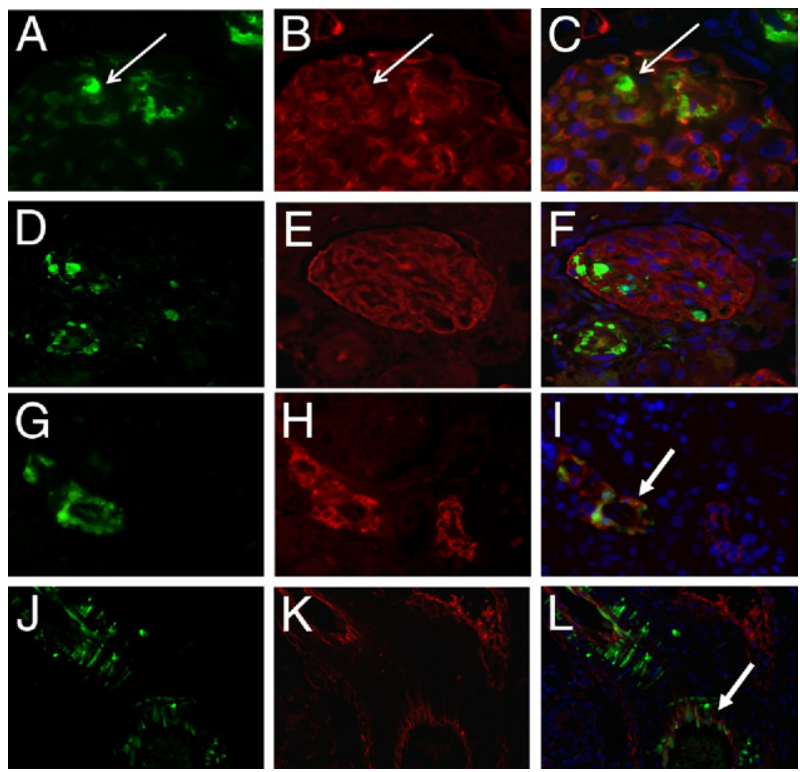

Figure 1. Localization of adenovirus-mediated transgene expression 7 days after GFP gene transfer. A-C: In the glomerulus, dual immunofluorescence for GFP (green) and CD34 (red) demonstrates endothelial colocalization (arrows). D-F: Dual immunofluorescent staining for GFP (green) and synaptopodin (red) shows increased glomerular GFP staining with no overlap with synaptopodin staining. G-I: In the interstitium, dual immunofluorescence for GFP (green) and $\alpha$-SMA (red) demonstrates colocalization (arrow in I). J-L: GFP and CD34 dual staining demonstrates some endothelial uptake in the interstitial arterioles (arrow in $\mathbf{L}$ ). Original magnification: $\times 400(\mathbf{A}-\mathbf{C}$ and $\mathbf{G}-\mathbf{L}) ; \times 100(\mathbf{D}-\mathbf{F})$ 
A

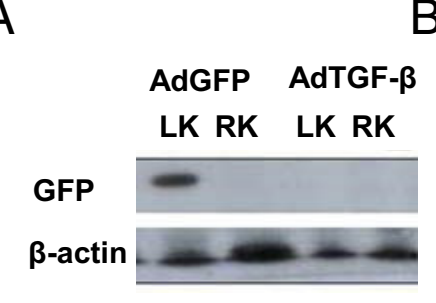

$B$

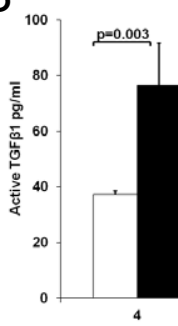

E
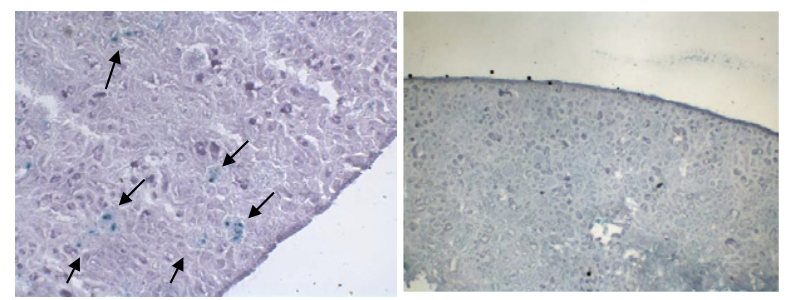

$\mathrm{G}$

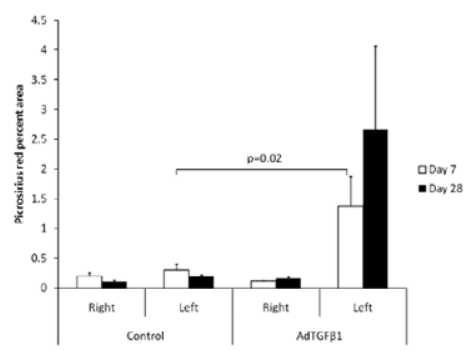

C

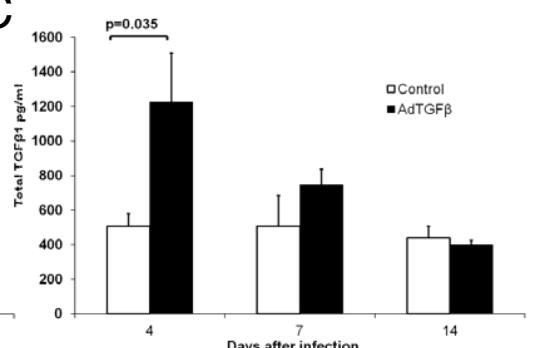

$\mathrm{F}$
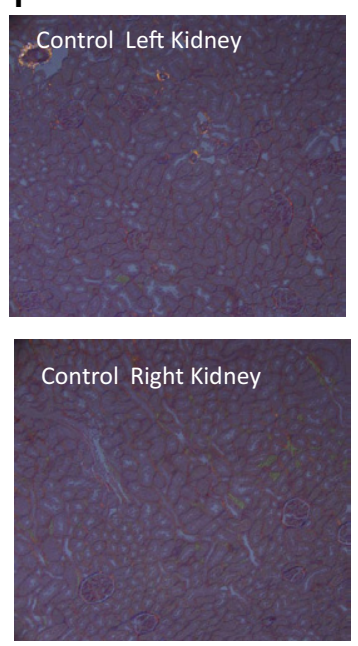

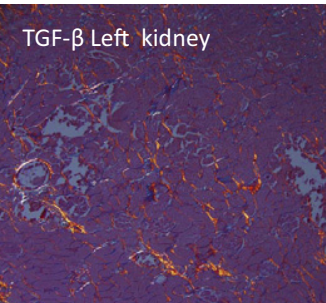

TGF- $\beta$ Right Kidney

Figure 2. A: GFP expression measured by using Western blot analysis of whole kidney homogenate in animals treated with AdGFP or AdTGF- $\beta 1$. Expression was evident in the left kidney (LK) of AdGFP-treated animals, with no expression seen in the right kidney (RK) or in animals treated with AdTGF- $\beta 1$. Active (B) and total (C) TGF- $\beta 1$ was measured in the urine by an enzyme-linked immunosorbent assay. There was a significant, transient TGF- $\beta 1$ excretion in the urine of AdTGF- $\beta 1$-treated rats. D and E: Animals were treated with AdLacZ. There was evidence of adenoviral expression in $75 \%$ of the glomeruli in the LacZ-infected left kidney ( $\mathbf{D}$, arrows indicate glomeruli staining positive for $\beta$-galactosidase), with no expression in the right kidney (E). F: Picrosirius red staining of renal tissue demonstrates a significant increase in interstitial fibrosis in the left kidney of animals treated with AdTGF- $\beta 1$. G: Birefringence was quantified, and results are shown.
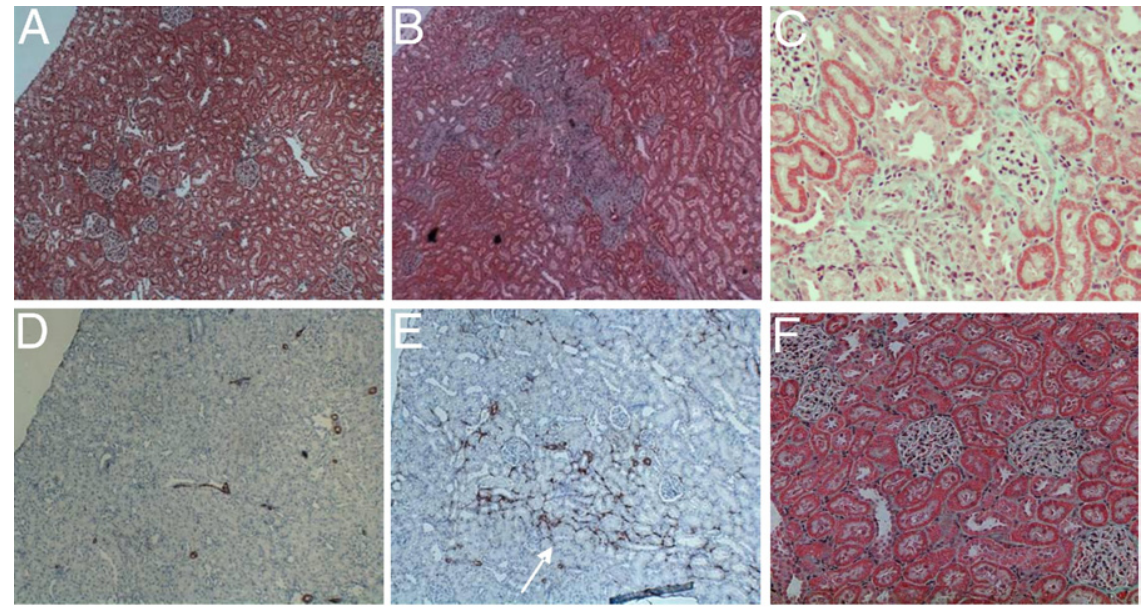

Figure 3. Renal histological features after adenoviral infection. A and B: Masson's trichrome staining of left kidney 7 days after treatment with AdGFP (A) or AdTGF- $\beta 1$ (B). After AdGFP, the kidney reveals normal histological features. B Patchy interstitial fibrosis is observed 7 days after AdTGF- $\beta 1$ treatment in the left kidney. C: Higher-power view of interstitial fibrosis. $\mathbf{D}$ and $\mathbf{E}$ : $\alpha$-SMA staining of AdGFP-treated left kidney on day 7 (D) shows perivascular $\alpha$-SMA staining only. Seven days after AdTGF- $\beta 1$ treatment $(\mathbf{E})$, the left kidney demonstrated patchy interstitial $\alpha$-SMA expression (arrow in $\mathbf{E}$ ). $\mathbf{F}$ and $\mathbf{G}$ : Masson's trichrome staining of glomeruli from AdGFP-treated $(\mathbf{F})$ and AdTGF- $\beta 1$-treated $(\mathbf{G}$ animals reveals normal histological features. Original magnification: $\times 50(\mathbf{A}, \mathbf{B}, \mathbf{D}$, and $\mathbf{E})$; $\times 400(\mathbf{C})$; and $\times 200(\mathbf{F}$ and $\mathbf{G})$. The right kidneys (untreated) of both AdGFP- and AdTGF- $\beta$ treated animals demonstrated normal histological features (data not shown). 
dehydrated and embedded in Spurr's epoxy resin. Sections were stained with uranyl acetate, followed by lead citrate, and viewed with a Jeol 1200 electron microscope (Jeol, Kanata, ON, Canada). Twenty electron micrographs were taken at random for each sample, and podocyte foot process density was measured using Northern Eclipse image processing software (Empix Imaging).

\section{Protein Assays}

For transgene quantification, kidney homogenate was run on an SDS-PAGE gel and probed with anti-GFP antibody (Santa Cruz Biotechnology). $\beta$-Actin (SigmaAldrich) was used as a loading control. Urine was collected in a metabolic cage over 6 hours. Animals had access to water during this time. Urine was assayed for creatinine and total protein using a standard diagnostic platform (Roche Diagnostics, Laval, QC, Canada). Equal volumes of urine samples were electrophoresed on an SDS-PAGE gel and stained with Coomassie Blue. Nephrin was measured in the urine by probing electrophoresed urine with an anti-nephrin antibody (Abcam, Cambridge, MA). Band density was measured using Scion Image Software (Scion Corp, Frederick, MD) and corrected for urine creatinine concentration.

TGF- $\beta 1$ was measured in urine samples using an enzyme-linked immunosorbent assay (R\&D Systems). Samples were run directly to measure active TGF- $\beta 1$. For total TGF- $\beta 1$, samples were activated for 10 minutes with $\mathrm{HCl}$, then $\mathrm{pH}$ adjusted with $\mathrm{NaOH}$ before assaying.
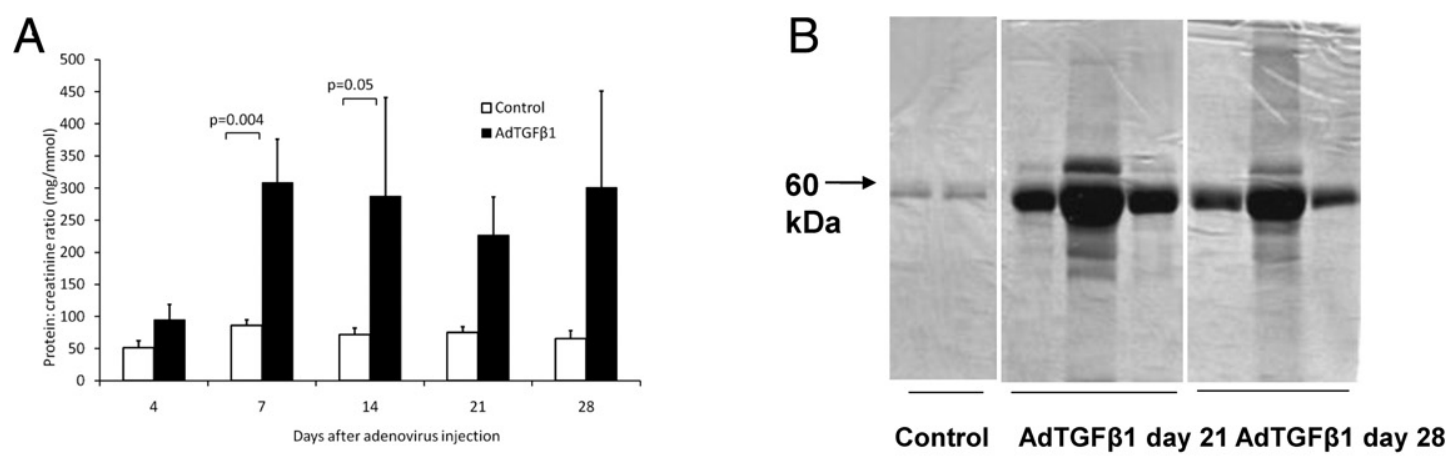

C
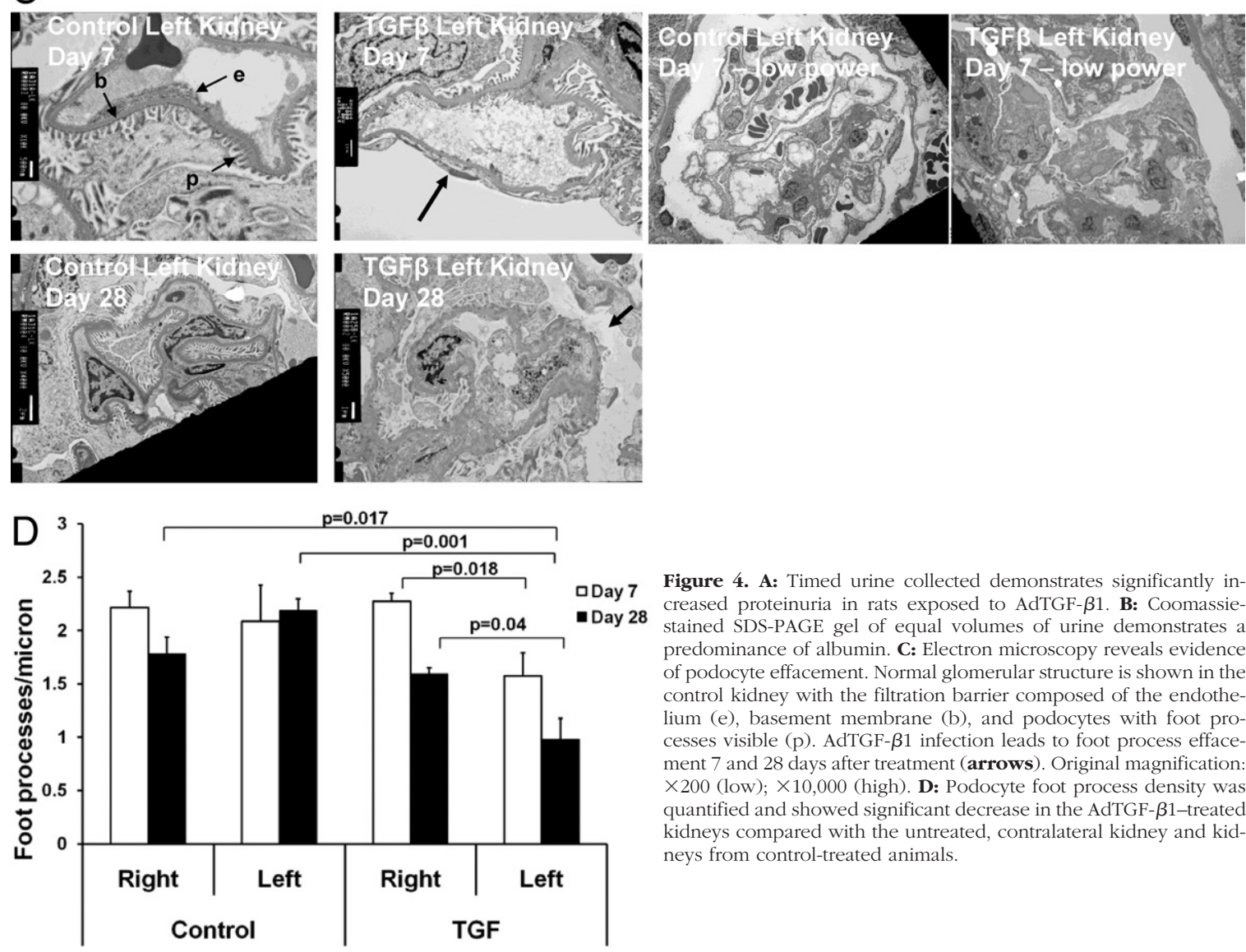

Figure 4. A: Timed urine collected demonstrates significantly in-

creased proteinuria in rats exposed to AdTGF- $\beta 1$. B: Coomassiestained SDS-PAGE gel of equal volumes of urine demonstrates a predominance of albumin. C: Electron microscopy reveals evidence of podocyte effacement. Normal glomerular structure is shown in the control kidney with the filtration barrier composed of the endothelium (e), basement membrane (b), and podocytes with foot processes visible (p). AdTGF- $\beta 1$ infection leads to foot process effacement 7 and 28 days after treatment (arrows). Original magnification: $\times 200$ (low); $\times 10,000$ (high). D: Podocyte foot process density was quantified and showed significant decrease in the AdTGF- $\beta 1$-treated kidneys compared with the untreated, contralateral kidney and kidneys from control-treated animals. 


\section{Laser-Capture Microdissection of Glomerular Tissue and RNA Extraction}

Frozen sections of the left kidney ( $8 \mu \mathrm{m}$ thick) were used for laser microdissection (LCM). The glomeruli were identified based on morphological characteristics and were captured using a PixCell II System (Arcturus, Mountain View, CA).

RNA from laser-captured tissue was extracted using a Pico Pure RNA Isolation Kit (Arcturus), followed by amplification using a Message Amp aRNA Kit (Ambion, Austin, TX). The RNA from LCM tissue was reverse transcribed using a standard protocol (Invitrogen, Burlington, ON, Canada). Quantitative real-time PCR was performed using an ABI Prism 7500 Sequence Detector (Applied Biosystems, Foster City, CA). Pooled mRNA from control animals was used to generate a standard curve for comparative quantification. The correlation coefficient for the standard curves for all samples was $>0.90$. Samples were run in duplicate. Negative control samples (no template or no reverse transcriptase) were run concurrently. Results were referenced to $\beta-2$ microglobulin expression.

\section{Cell Culture}

Immortalized podocytes were a gift from Dr. Peter Mundel (Department of Medicine, University of Miami Miller School of Medicine, Miami, FL) and were cultured as previously described. ${ }^{24}$ For all experiments, podocytes were serum starved for 12 hours before treatment. These cells were exposed to different concentrations of recombinant TGF- $\beta 1$ ( $r$ TGF- $\beta 1$; R\&D Systems) for 8 hours. Cells were also treated with $\mathrm{rTGF}-\beta 1(5 \mathrm{ng} / \mathrm{mL})$ and anti-human Ang1, Ang2 antibody, or a blocking anti-Tie2 antibody
(R\&D Systems). Cell lysates were then analyzed by using Western blot analysis and probed for Tie2 (R\&D Systems), nephrin (Abcam), podocin (Abcam), or synaptopodin (Progen Biotechnik). Podocytes were also exposed to $\mathrm{rTGF}-\beta$ at $5 \mathrm{ng} / \mathrm{mL}$ with cyclosporine $(1 \mu \mathrm{g} / \mathrm{mL}$; Sigma) for 8 hours. Cell lysates were taken and assayed for synaptopodin or Zo-1 (Zymed Laboratories, San Francisco, CA). Three samples were assayed for each condition, and the experiments were repeated in duplicate.

Small-interfering RNA (siRNA) against Tie2 (Stealth; Invitrogen) or nontargeting siRNA was transfected into immortalized podocytes. Twenty-four hours after transfection, cells were treated with rTGF- $\beta 1$ at $5 \mathrm{ng} / \mathrm{mL}$ for 8 hours. Cell lysates were assayed for synaptopodin or nephrin by using Western blot analysis.

Immortalized mouse cardiac endothelial cells (MCEC; Cedarlane, Burlington, ON, Canada) were grown on $0.2 \%$ gelatin-coated plates. When $80 \%$ confluent, cells were infected with AdDL (control adenovirus) or AdTGF- $\beta 1$ at 10 plaque-forming units per cell. Twenty-four hours later, cells were washed with PBS and fresh media were placed for 12 hours. These media were ultraviolet-lightinactivated and then placed on podocyte cells for 8 hours. Podocyte cell lysates were then taken and assayed for nephrin and synaptopodin by using Western blot analysis.

\section{Statistics}

Data are presented as mean \pm SEM. Groups were compared using an analysis of variance with Tukey's post hoc test. Data were analyzed using SPSS version 17.0 software (SPSS, Chicago, IL). $P<0.05$ was considered significant.
A

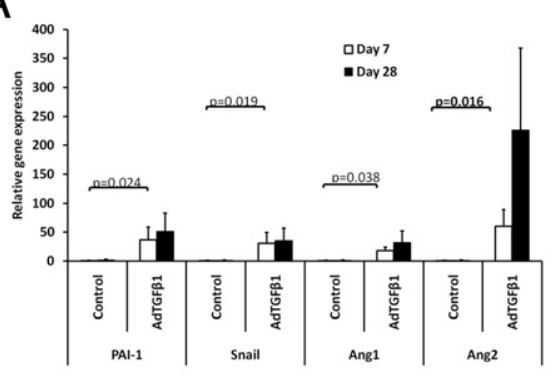

D

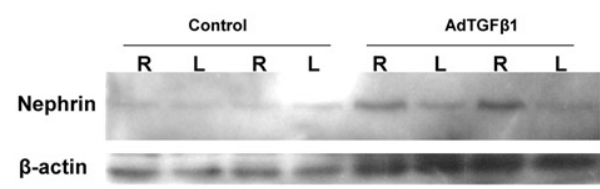

$\mathrm{B}$

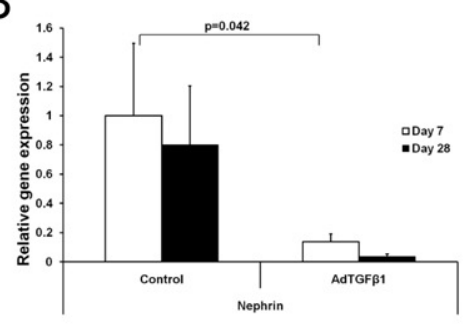

$\mathrm{E}$

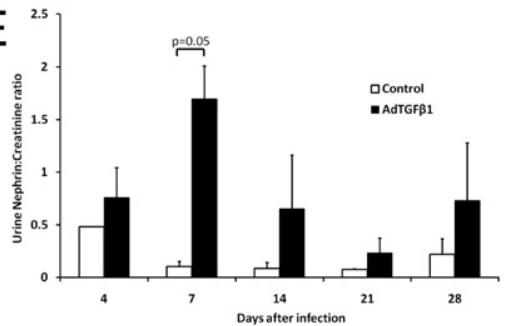

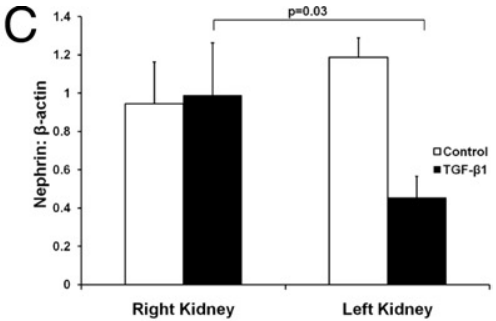

$\mathrm{F}$

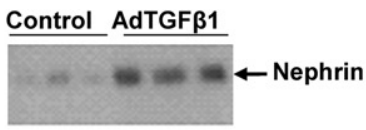

Figure 5. A and B: Laser-capture microdissection of glomerular tissue from left kidneys of animals treated with AdTGF- $\beta 1$ or control adenovirus. A: There was a significant up-regulation of plasminogen activator inhibitor (PAI)-1, Snail, Ang1, and Ang2 at 7 days after adenovirus infection. B: There was a significant down-regulation of the gene expression of the podocyte adhesion molecule nephrin. $\mathbf{C}$ and $\mathbf{D}$ : Western blot analysis of whole kidney homogenate 7 days after infection with control adenovirus or AdTGF- $\beta 1$ demonstrates decreased nephrin expression only in the treated (left) kidneys. D: Representative blot (L, left kidney; R, right kidney). E and F: Nephrin is significantly increased in the urine of rats treated with AdTGF- $\beta 1$. Nephrin was measured in the urine by using Western blot analysis $(\mathbf{F})$, and the relative band density from the Western blot analysis was normalized to urine creatinine. 


\section{Results}

\section{Animal Model}

AdTGF- $\beta 1$ was slowly perfused into the left kidneys of Sprague-Dawley rats via an intra-arterial approach, with AdGFP used as a control. Seven days after transfection, GFP expression was observed in the glomeruli and vasculature of the perfused left kidney (Figure 1). We did not observe any GFP expression in the right kidney, spleen, or lung, but it was expressed in the liver. Twenty-eight days after infection, we found decreased, but persisting, expression of GFP in the left kidney.

We used dual immunofluorescence to assess cellular localization of adenovirus-delivered GFP (Figure 1). Seven days after gene transfer, there was significant expression localized to CD34-positive endothelial cells of the glomeruli (Figure 1, A-C). There was no colocalization with synaptopodin-positive podocytes (Figure 1, D-F). In the interstitium, we observed expression in the vascular structures that colocalized with $\alpha$-SMA-positive perivascular (Figure 1, G-I) and CD34-positive endothelial (Figure $1, \mathrm{~J}-\mathrm{L}$ ) cells. We confirmed that expression was limited to the left kidney using whole tissue homogenate and examining for GFP expression (Figure 2A).

We measured the urinary concentration of TGF- $\beta 1$ using an enzyme-linked immunosorbent assay (Figure 2, B and $\mathrm{C}$ ). Active TGF- $\beta 1$ concentration was transiently increased in the urine of AdTGF- $\beta 1$-treated animals. Total urinary TGF- $\beta 1$ was increased significantly 4 days after infection, returning back to baseline at 14 days after infection (Figure 2C).

We confirmed the extent of expression in the adenovirus-infected kidneys in a small group of animals treated with AdLacZ. $\beta$-Galactosidase expression was found in approximately $75 \%$ of glomeruli (Figure 2D) of the left kidney, with no expression seen in the right kidney (Figure 2E).

There was an increase in renal fibrosis in the left kidneys of TGF- $\beta 1$-treated animals, as demonstrated by picrosirius red staining (Figure 2, F and $G$ ). There was no fibrosis seen in the right kidney of AdTGF- $\beta 1$-treated animals or in either kidney of control adenovirus-treated animals.

The control adenovirus-treated kidneys displayed no histological changes at day 7 or 28 after treatment (Figure 3A). $\alpha$-SMA expression was confined to the vascular smooth muscle cells of the renal interstitium (Figure 3D). AdTGF- $\beta 1$ induced a mild interstitial fibrosis manifested by collagen accumulation and increased $\alpha$-SMA expression (Figure 3, B, C, and E). On light microscopy, there were no changes identified in the glomeruli in either control adenovirus or AdTGF- $\beta 1$-treated kidneys (Figure 3, F and $\mathrm{G}$ ). Furthermore, the right (untreated) kidneys of both AdGFP- and AdTGF- $\beta 1$-treated animals had normal histological features (data not shown).

\section{Proteinuria and Podocyte Effacement}

Animals treated with AdTGF- $\beta 1$ demonstrated an increase in protein excretion (Figure 4, A and B), as as- sessed by a timed urine protein:creatinine ratio. Urine electrophoresis primarily showed a $65-\mathrm{kDa}$ protein in AdTGF- $\beta 1$-treated animals, suggesting predominant albuminuria. This increased protein excretion was associated with changes in the podocyte phenotype. On electron microscopy, there was significant podocyte effacement (Figure 4C). This was quantified (Figure 4D),
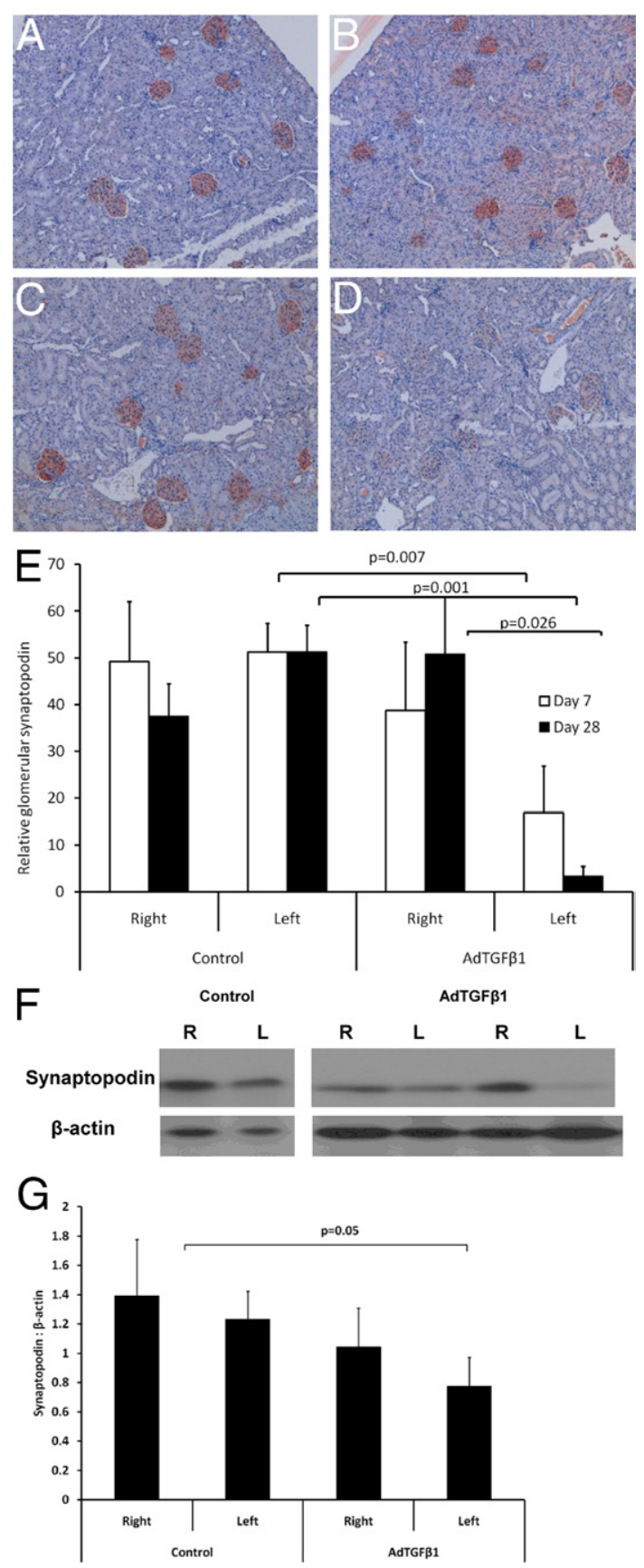

Figure 6. Kidney sections were stained for synaptopodin. Right (A) and left (B) kidneys from control adenovirus-treated animals at day 7. Right (C) and left (D) kidneys from AdTGF- $\beta 1$-treated animals. Glomerular staining density was quantified (E) and demonstrated significantly decreased staining in glomeruli of the left kidney of AdTGF- $\beta 1$-treated animals. Original magnification, $\times 50$. F: Synaptopodin protein was assessed from whole kidney homogenates using Western blot analysis and quantified in G. AdTGF- $\beta 1-$ treated kidneys demonstrated a significant down-regulation of synaptopodin protein. L, left kidney; R, right kidney. 
and there was a significant decrease in the podocyte foot process density in the left versus the right kidneys of AdTGF- $\beta 1$-treated animals. We did not see any evidence of apoptosis of podocytes or endothelial cells on lowpower electron microscopy sections (Figure 4C).

\section{Glomerular Gene and Protein Expression}

Glomeruli were isolated from renal tissue using laser-capture microdissection (Figure 5). There was a significant increase in gene expression of the TGF- $\beta 1$-responsive cytokine plasminogen activator inhibitor- 1 at 7 days after AdTGF- $\beta 1$ compared with control adenovirus kidneys (Figure 5A). There was also a significant induction of the EMTassociated regulatory protein Snail. Angiogenic cytokines Ang1 and Ang2 were also up-regulated.

There was a concurrent decrease in gene expression of the epithelial slit diaphragm protein nephrin (Figure 5B) in kidneys exposed to AdTGF- $\beta 1$. From whole tissue homogenates, we found that nephrin protein expression was significantly decreased in the left kidney of AdTGF$\beta 1$-treated animals after 28 days (Figure $5, C$ and D). Of interest, a significant increase in nephrin protein was observed in the urine of animals treated with AdTGF- $\beta 1$ (Figure 5, E and F). We also assessed the expression of the podocyte-associated protein synaptopodin using $\mathrm{IHC}$ (Figure 6, A-D). There was a significant decrease in synaptopodin expression in the left kidney of animals treated with AdTGF- $\beta 1$ (Figure 6E). This change was not seen in the right kidney of these animals or in the glomeruli of control animals. This down-regulation was also found in whole kidney tissue homogenates using Western blot analysis (Figure 6, F and G).

\section{Interaction between TGF- $\beta 1$ and Angiopoietins}

We assessed the effects of TGF- $\beta 1$ on cultured podocytes. Because of our observations of angiogenic gene regulation after AdTGF- $\beta 1$ gene transfer to the kidney, we hypothesized that angiopoietins may be involved in
A

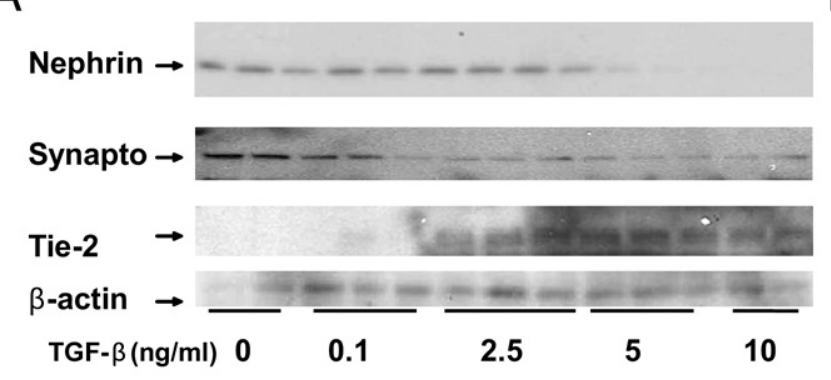

B

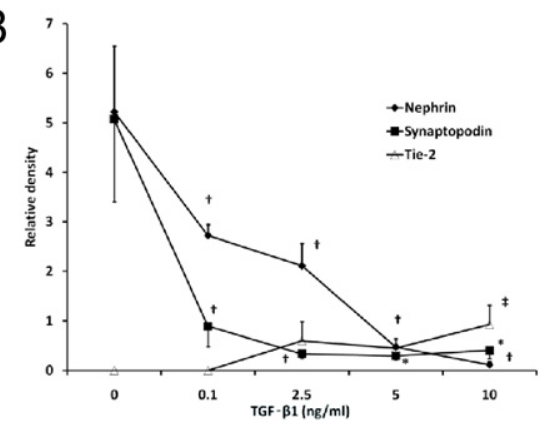

C
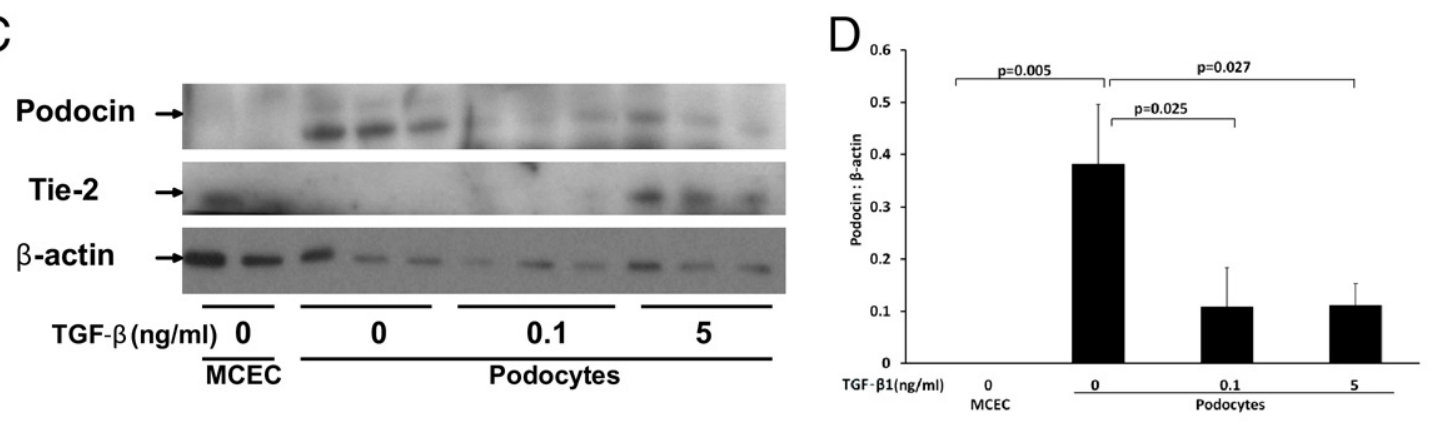

E

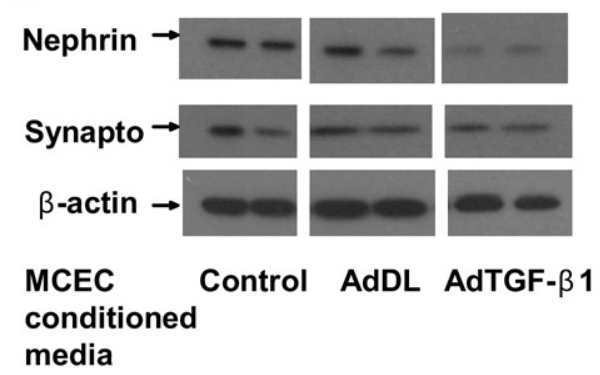

$\mathrm{F}$

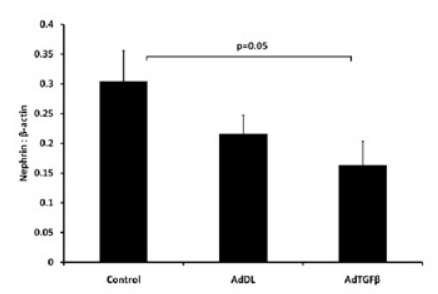

G

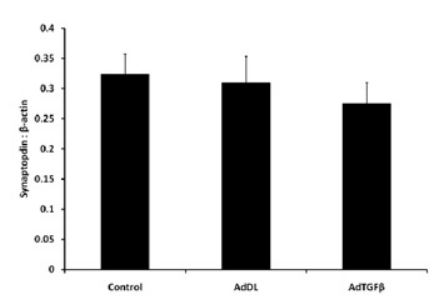

Figure 7. A: Immortalized podocytes were treated with rTGF- $\beta 1$. B: TGF- $\beta 1$ significantly inhibited nephrin and synaptopodin expression in a dose-response manner, while increasing the expression of the angiopoietin receptor Tie 2 . ${ }^{*} P<0.001,{ }^{\dagger} P<0.01$, and ${ }^{\ddagger} P<0.05$ versus untreated cells. $\mathbf{C}$ and $\mathbf{D}$ : Podocin was also significantly down-regulated by TGF- $\beta 1$. Untreated mouse cardiac endothelial cells (MCEC) were used as a positive control for Tie 2 expression. E: MCECs were grown to confluence and exposed to AdDL, AdTGF- $\beta 1$, or no adenovirus (Control). Conditioned media were then added to podocyte culture. F: Nephrin expression was significantly down-regulated by MCEC media condition with AdTGF- $\beta 1$. G: Synaptopodin expression was not significantly affected. 
A

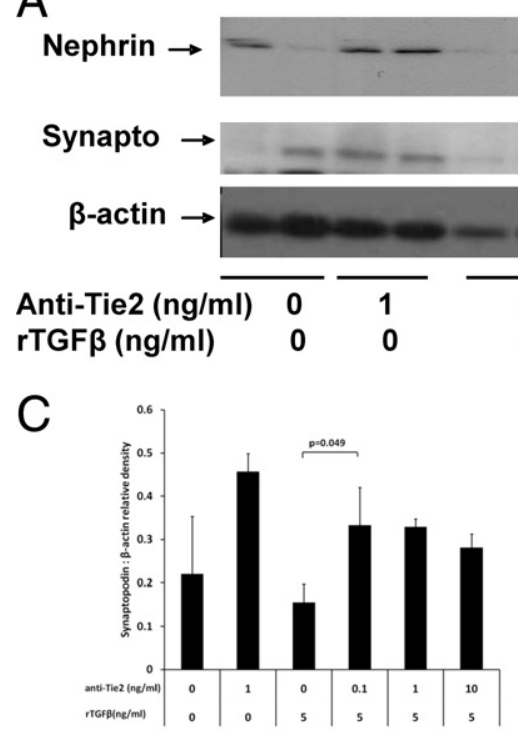

E

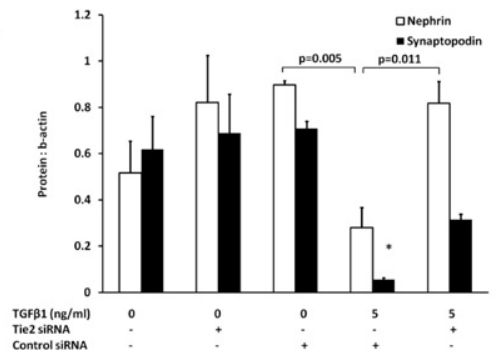

B

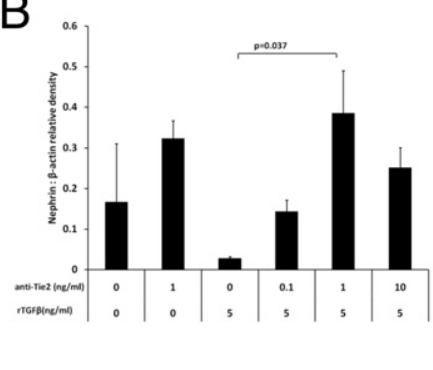

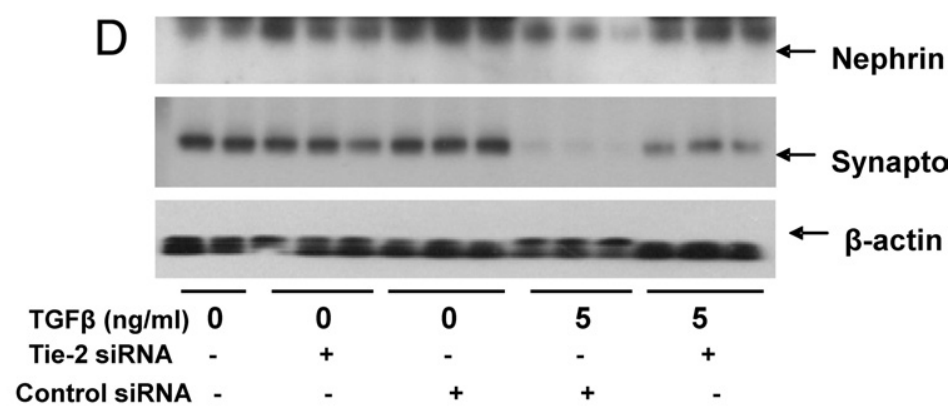

Figure 8. A: Podocytes were treated with rTGF- $\beta(5 \mathrm{ng} / \mathrm{mL})$ concurrently with increasing doses of an antibody against Tie 2 . Tie 2 antibody was able to reverse the TGF- $\beta$-induced inhibition of nephrin (B) and synaptopodin $(\mathbf{C})$. D: Podocytes were treated with rTGF- $\beta$ $(5 \mathrm{ng} / \mathrm{mL})$ and siRNA for Tie2 (controlled with nontargeting siRNA). E: SiRNA to Tie2 also reversed the TGF- $\beta$-induced inhibition of nephrin and synaptopodin. ${ }^{*} P<0.01$ versus all other groups.

podocyte changes induced by TGF- $\beta 1$. We found that rTGF- $\beta 1$ suppressed the expression of nephrin and synaptopodin in a dose-dependent manner (Figure 7, A and B). TGF- $\beta 1$ also significantly increased the expression of the angiopoietin receptor Tie2 (Figure 7, A and B). In a separate experiment, we confirmed the increased expression of Tie2 by TGF- $\beta 1$ (using MCEC as a positive control) and also found that the associated slit diaphragm protein podocin was down-regulated by TGF- $\beta 1$ (Figure $7, \mathrm{C}$ and D).

We demonstrated that the virus mainly infected CD34positive endothelial cells (Figure 1, A-C). We, therefore, attempted to mimic this in vitro by infecting MCEC with AdTGF- $\beta 1$ and exposing podocytes to this conditioned media. We found that, after infection with AdTGF- $\beta 1$, MCEC-conditioned media significantly down-regulated nephrin expression in podocytes (Figure 7, E and F). The effect on synaptopodin expression was not as obvious (Figure 7G).

The TGF- $\beta 1$-induced down-regulation of nephrin and synaptopodin could be reversed by an antibody against anti-Tie2 (Figure 8, A-C). There was a dose-response between 0 and $1 \mathrm{ng} / \mathrm{mL}$ of anti-Tie2 antibody but no additional effect at $10 \mathrm{ng} / \mathrm{mL}$. Furthermore, we could block the effect of TGF- $\beta 1$ on podocytes using an siRNA against Tie2 (Figure 8D). In this experiment, podocytes were transfected with siRNA against Tie2 or a control siRNA. TGF- $\beta 1$ significantly reduced nephrin and synaptopodin expression, and this effect was reversed with siRNA against Tie2 (Figure 8E). The nonspecific siRNA had no effect.

An antibody against Ang1 significantly blocked the TGF- $\beta 1$ down-regulation of nephrin and synaptopodin (Figure 9, A-C). An antibody against Ang2 significantly reversed the TGF- $\beta 1$ down-regulation of nephrin (Figure $9, \mathrm{D}$ and $\mathrm{E}$ ) but did not block the effect on synaptopodin (Figure 9F).

It was previously demonstrated that cyclosporine can prevent cathepsin-L-mediated degradation of synaptopodin. ${ }^{25}$ We, therefore, exposed podocytes to both TGF- $\beta 1$ (Figure 10A) and cyclosporine (Figure 10B) and found that cyclosporine was able to block the TGF- $\beta 1-$ mediated down-regulation of synaptopodin (Figure 10B) but had no effect on Zo-1, a tight junction-associated epithelial protein (Figure 10C).

\section{Discussion}

The molecular basis of proteinuria in common renal diseases, such as diabetes or chronic glomerulonephritis, has yet to be fully elucidated. Glomerular hypertension, hyperglycemia, and an increase in local angiotensin II expression are common findings in proteinuric renal disease. ${ }^{26}$ These factors have all led to increased expression of TGF- $\beta,{ }^{27}$ suggesting that TGF- $\beta$ may play a sig- 
A

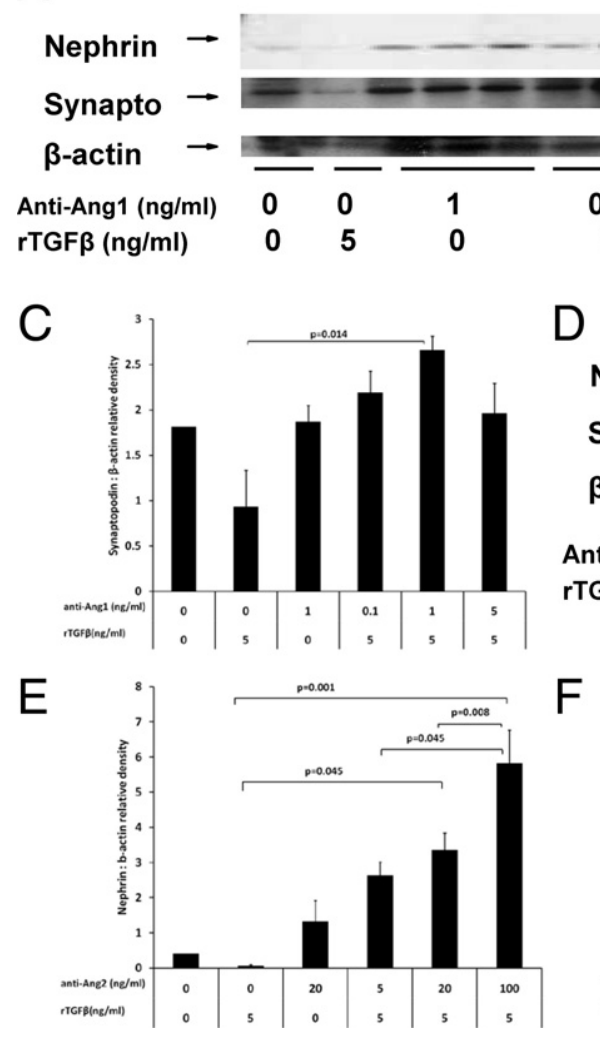

D

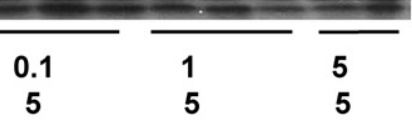

B

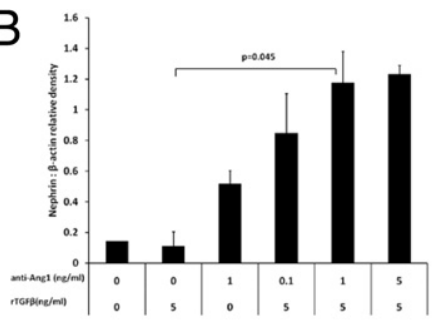

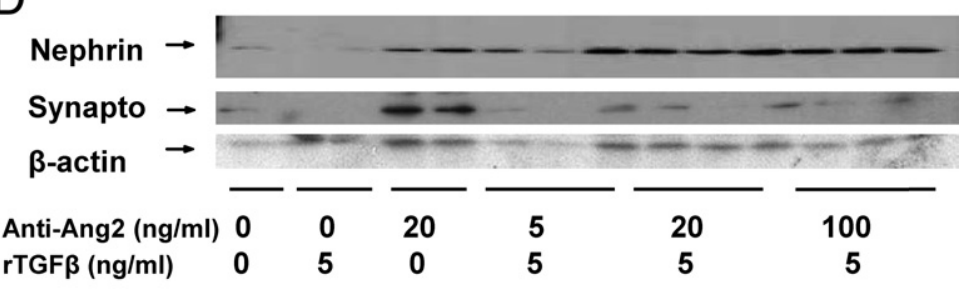

F

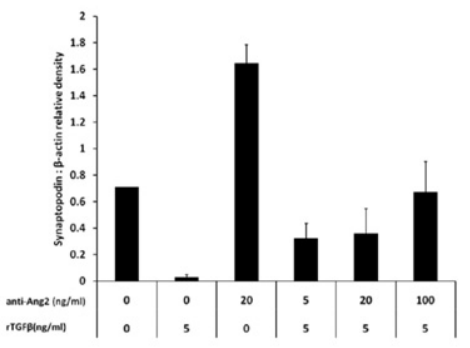

Figure 9. A: Podocytes were treated with rTGF- $\beta(5 \mathrm{ng} / \mathrm{mL})$ concurrently with increasing doses of an antibody against Ang1. B and C: Ang1 antibody was able to reverse the TGF- $\beta$-induced inhibition of nephrin (B) and synaptopodin (C). D: Similar experiment but with increasing doses of an antibody against Ang2. E and F: Ang2 antibody was able to reverse the TGF- $\beta$-induced inhibition of nephrin (E) but not synaptopodin (F). nificant role in alterations of the glomerular filtration barrier.

We have adopted a novel model of TGF- $\beta$ overexpression in the kidney. By using a slow perfusion method to infect the kidney with adenoviruses expressing TGF- $\beta$, GFP, or $\beta$-galactosidase, we demonstrated renal-specific expression. The technique we adopted was first described by $\mathrm{Ye}$ et $\mathrm{al},{ }^{28}$ and has also been used successfully in larger animals. ${ }^{29}$ Similar to our findings, these studies demonstrated that up to $75 \%$ of glomeruli expressed the transgene and the expression lasted up to 21 days. ${ }^{29}$ We observed a diffuse uptake of adenovirus in glomeruli and peritubular capillaries. We were able to detect transgene expression in the urine up to 7 days after infection (Figure 2). One benefit of this approach is that we selectively infect the left kidney, leaving the right kidney as an internal control. There is liver uptake and expression of the adenovirus using this technique (data not shown). ${ }^{29}$ In our experiments, there was no evidence of a systemic effect of TGF- $\beta$ expression in the animals treated with AdTGF- $\beta$; the control right kidney did not show any of the effects seen in the infected left kidney.

There have been previous reports of the effects of systemic TGF- $\beta$ on the structure and function of the kidney. Systemic overexpression of TGF- $\beta$ appears to have an impact on the kidney through either a hemodynamic, vasoconstrictive mechanism ${ }^{30}$ or a direct fibrogenic effect. $^{31}$ In a previous report, ${ }^{20}$ high levels of systemic TGF- $\beta$ using a transgenic mouse model had a proteinuric effect, but the mechanism of this renal injury was not described. Krag et $\mathrm{al}^{21}$ described a novel transgenic mouse with TGF- $\beta$ driven from the Ren $-1^{c}$ promoter of the juxtaglomerular apparatus, which developed albuminuria. In an earlier publication, Wogensen et $\mathrm{al}^{32}$ included electron micrographs revealing extensive podocyte effacement similar to our study, but this phenomenon was not commented on in the article. Other studies have used proximal tubule promoter ${ }^{33}$ or gene transfer of TGF- $\beta{ }^{34}$ but the effect on protein excretion was not addressed.

We have demonstrated that transient overexpression of TGF- $\beta 1$ primarily in the glomerular endothelium leads to podocyte effacement and proteinuria. The resulting phenotypic change of podocytes was associated with a glomerular-specific increase in the regulatory protein Snail, as measured in laser-capture microdissected samples (Figure 5). We also observed a decrease in podocyte-specific markers nephrin, synaptopodin, and podocin (Figures 5 and 6), along with suppression of the epithelial marker Zo-1 (Figure 10). These findings are indicative of a dedifferentiation or EMT-like process. Recently, TGF- $\beta 1$ has induced dedifferentiation and features consistent with EMT in podocytes. ${ }^{3}$ Li et al ${ }^{3}$ argue that this dedifferentiation may explain proteinuria in many clinical conditions. We have extended their findings with our in vivo evidence of this process. Podocyte dedifferentiation appears to be an early event in glomerular injury and subsequent podocyte apoptosis and sloughing has been observed in advanced renal disease. ${ }^{4}$ However, this podocytopathy appears to be a later finding that occurs after the onset of proteinuria. ${ }^{35}$ The role of Snail in nephrin gene transcription repression has been demonstrated in a model of puromycin-induced nephrosis. ${ }^{36}$ 

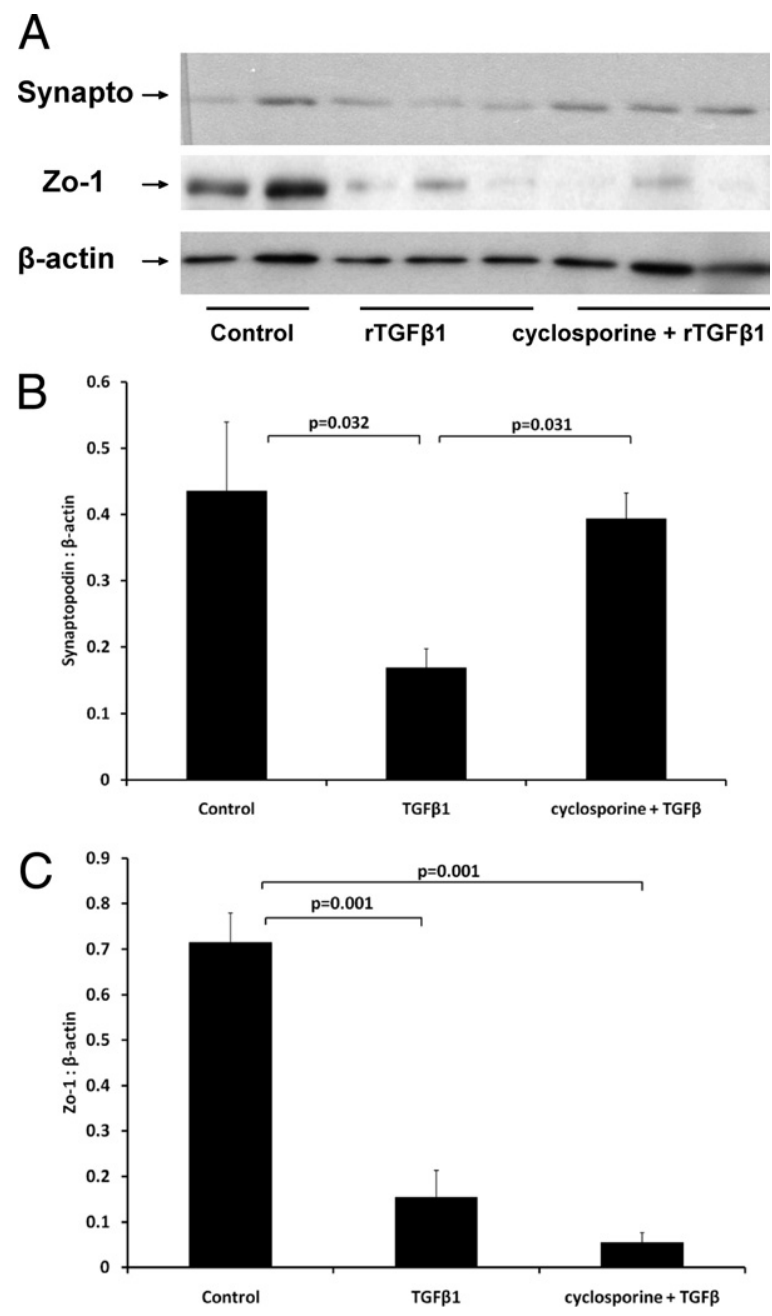

Figure 10. A: Podocytes were treated with TGF- $\beta(5 \mathrm{ng} / \mathrm{mL})$ and cyclosporine $(1 \mu \mathrm{g} / \mathrm{mL})$. B: As previously demonstrated, TGF- $\beta$ down-regulated synaptopodin, and this effect was blocked by cyclosporine. C: The epithelial protein Zo-1 was also down-regulated by TGF- $\beta$, and this was not reversed by cyclosporine.

Podocyte EMT has also been suggested in a recent study $^{37}$ in patients in whom the mesenchymal marker fibroblast specific protein 1 was identified in podocytes in the urine of those with diabetes.

We observed a TGF- $\beta$-mediated down-regulation of synaptopodin in our model. Synaptopodin is involved with the structure of the actin cytoskeleton and is of critical importance for the maintenance of the podocyte slit diaphragm. Decreased synaptopodin expression has been associated with proteinuria ${ }^{14,25}$ and is related to steroid unresponsiveness in primary focal segmental glomerulosclerosis. ${ }^{38}$ Abbate et $\mathrm{al}^{39}$ found that injury to podocytes in a remnant kidney model led to increased TGF- $\beta$ expression and loss of synaptopodin. In a study by Lai et $\mathrm{al}^{40}$ human mesothelial cells were exposed to pathogenic IgA and podocytes were then grown in the presence of this conditioned media. They observed a down-regulation of podocin and synaptopodin. The down-regulation of nephrin by this conditioned medium could be blocked by antibodies to TGF- $\beta$, but the effects on synaptopodin were not assessed. Furthermore, high glucose has down-regulated synaptopodin, and this was demonstrated to be inhibited by bone morphogenic protein 7 , which is a TGF- $\beta$ antagonist. ${ }^{41}$

Recent work ${ }^{42}$ has identified the central role of cathepsin L-mediated proteolytic cleavage of synaptopodin in proteinuria. Sever et $\mathrm{al}^{43}$ identified a cytoplasmic form of cathepsin L, which induced dynamin degradation. Proteinuria was inhibited when cathepsin $L$ was blocked. ${ }^{43}$ Further work by Faul et $\mathrm{al}^{25}$ showed a novel, nonimmunological role for cyclosporine in preventing cathepsin $\mathrm{L}-$ mediated degradation of synaptopodin. Most recently, Yaddanapudi et $\mathrm{al}^{44}$ identified a role for TGF- $\beta$ induction of cathepsin L in CD2AP knockout mice. Our experiments provide further evidence of TGF- $\beta$-induced down-regulation of synaptopodin. We also found that TGF- $\beta 1-$ mediated down-regulation of synaptopodin could be prevented with cotreatment with cyclosporine. Cyclosporine did not prevent the TGF- $\beta 1$-mediated down-regulation of Zo-1, suggesting a specific action of cyclosporine on synaptopodin.

The loss of nephrin expression in the glomeruli, along with the increase of urine nephrin, is further evidence for direct damage or dedifferentiation of podocytes in our model. The potential of increased urinary nephrin as a marker of podocyte injury has been previously shown. ${ }^{45}$ Indeed, urine nephrin excretion has been observed early in the course of experimental nephritis, even before overt proteinuria. ${ }^{46}$

Angiopoietins are known to modify the angiogenic effects of VEGF. In quiescent vasculature, Ang1 is produced by perivascular cells and has a paracrine effect on endothelial cells. Ang1 binds to the Tie2 receptor and signals through phosphatidylinositol 3-kinase/Akt to maintain vascular integrity. ${ }^{47}$ In pathological settings, VEGF and Ang2 are up-regulated and lead to vascular destabilization, angiogenic sprouting, and new vessel formation. ${ }^{48}$ Ang 2 similarly binds to the Tie2 receptor and is believed to be an antagonist for Ang1. In the glomerulus, the role of the angiopoietins is not clearly defined. ${ }^{49}$ In the quiescent state, Ang1 and VEGF are produced by podocytes and have protective and anti-proteinuric effects on endothelial cells. ${ }^{8,50}$

Ang2 has been associated with proteinuria and renal injury in several settings, including lupus nephritis ${ }^{51}$ and diabetic nephropathy. ${ }^{26}$ In previous work, Davis et $\mathrm{al}^{5}$ generated a mouse model in which Ang2 was overexpressed on a podocyte-specific promoter. In this model, Ang2 overexpression led to proteinuria and decreased nephrin expression, similar to what we found in our study. Interestingly, they did not describe phenotypic changes in podocytes in response to Ang2 but found that it induced endothelial cell dysfunction, which was believed to underlie the proteinuric response.

We identified that both Ang1 and Ang2 were up-regulated in the glomeruli from animals exposed to AdTGF- $\beta 1$ (Figure 5), similar to observations by Campean et $\mathrm{al}^{52}$ in the Thy 1.1 model of glomerular injury. In unstimulated podocytes, we found no expression of Tie2, but TGF- $\beta 1$ increased Tie2 expression in a dose-responsive manner (Figure 7). Tie2 expression is normally confined to endothelial cells, but two previous articles ${ }^{5,9}$ have described 
the expression of Tie2 on podocytes. The current understanding is that Ang1 is a Tie2 agonist, whereas Ang2 acts as an antagonist. ${ }^{48}$ In our experiments, we were able to block the inhibitory effect of TGF- $\beta$ on nephrin with an antibody and siRNA directed against Tie2, an antibody directed against Ang1, and an anti-Ang2 antibody. This suggests that Ang2 may have similar effects to Ang1 on podocytes. Ang2 agonist activity has been suggested in endothelial cells in some settings. ${ }^{53,54}$ Furthermore, in the original description of angiopoietin/Tie2 signaling, Ang2 may have acted as a Tie2 agonist in nonendothelial cells. ${ }^{48}$ Finally, angiopoietins may signal through other non-Tie2 mechanisms, such as integrins. ${ }^{55}$ The lack of podocyte effacement after Ang2 overexpression, as seen in the study by Davis et al, ${ }^{5}$ suggests that Ang2 alone is not sufficient to induce phenotypic changes in podocytes. We hypothesize that TGF- $\beta$ is required for podocyte dedifferentiation either as a direct cofactor or through the induction of Tie2 receptors on podocytes.

The role of angiopoietins in TGF- $\beta$-mediated podocyte dedifferentiation will need to be integrated with the observed effects of TGF- $\beta$ on cathepsin L-induced synaptopodin degradation and proteinuria. These may be steps within the same pathway, or they may represent separate simultaneous processes that augment the proteinuric effect of TGF- $\beta$.

In summary, we have developed a novel model of proteinuria and podocyte dedifferentiation that involves the isolated up-regulation of a single key profibrotic cytokine (TGF- $\beta 1$ ) in glomerular endothelial cells. The mechanism appears to involve an EMT-like phenomenon with increased expression of Snail and down-regulation of podocyte epithelial markers, such as nephrin and synaptopodin. The effects of TGF- $\beta 1$ are at least partly mediated by angiopoietins.

\section{References}

1. Ruggenenti P, Schieppati A, Remuzzi G: Progression, remission, regression of chronic renal diseases. Lancet 2001, 357:1601-1608

2. Tryggvason K, Patrakka J, Wartiovaara J: Hereditary proteinuria syndromes and mechanisms of proteinuria. N Engl J Med 2006, 354: $1387-1401$

3. Li Y, Kang YS, Dai C, Kiss LP, Wen X, Liu Y: Epithelial-to-mesenchymal transition is a potential pathway leading to podocyte dysfunction and proteinuria. Am J Pathol 2008, 172:299-308

4. Wolf G, Ziyadeh FN: Cellular and molecular mechanisms of proteinuria in diabetic nephropathy. Nephron Physiol 2007, 106:26-31

5. Davis B, Dei CA, Long DA, White KE, Hayward A, Ku CH, Woolf AS, Bilous R, Viberti G, Gnudi L: Podocyte-specific expression of angiopoietin-2 causes proteinuria and apoptosis of glomerular endothelia. J Am Soc Nephrol 2007, 18:2320-2329

6. Comper WD, Hilliard LM, Nikolic-Paterson DJ, Russo LM: Diseasedependent mechanisms of albuminuria. Am J Physiol Renal Physiol 2008, 295:F1589-F1600

7. Ly J, Alexander M, Quaggin SE: A podocentric view of nephrology. Curr Opin Nephrol Hypertens 2004, 13:299-305

8. Eremina V, Sood M, Haigh J, Nagy A, Lajoie G, Ferrara N, Gerber HP, Kikkawa Y, Miner JH, Quaggin SE: Glomerular-specific alterations of VEGF-A expression lead to distinct congenital and acquired renal diseases. J Clin Invest 2003, 111:707-716

9. Satchell SC, Harper SJ, Tooke JE, Kerjaschki D, Saleem MA, Mathieson PW: Human podocytes express angiopoietin 1, a potential regulator of glomerular vascular endothelial growth factor. J Am Soc Nephrol 2002, 13:544-550
10. Ballermann BJ, Stan RV: Resolved: capillary endothelium is a major contributor to the glomerular filtration barrier. J Am Soc Nephrol 2007, 18:2432-2438

11. Li ZD, Bork JP, Krueger B, Patsenker E, Schulze-Krebs A, Hahn EG, Schuppan D: VEGF induces proliferation, migration, and TGF-beta1 expression in mouse glomerular endothelial cells via mitogen-activated protein kinase and phosphatidylinositol 3-kinase. Biochem Biophys Res Commun 2005, 334:1049-1060

12. Lee YH, Kayyali US, Sousa AM, Rajan T, Lechleider RJ, Day RM: Transforming growth factor-beta1 effects on endothelial monolayer permeability involve focal adhesion kinase/Src. Am J Respir Cell Mol Biol 2007, 37:485-493

13. Patari A, Forsblom C, Havana M, Taipale H, Groop PH, Holthofer H: Nephrinuria in diabetic nephropathy of type 1 diabetes. Diabetes 2003, 52:2969-2974

14. Yanagida-Asanuma E, Asanuma K, Kim K, Donnelly M, Young $\mathrm{CH}$, Hyung CJ, Suetsugu S, Tomino Y, Takenawa T, Faul C, Mundel P: Synaptopodin protects against proteinuria by disrupting Cdc42: IRSp53:Mena signaling complexes in kidney podocytes. Am J Pathol 2007, 171:415-427

15. Cina DP, Xu H, Liu L, Farkas L, Farkas D, Kolb M, Margetts PJ: Renal tubular angiogenic dysregulation in anti-Thy 1.1 glomerulonephritis. Am J Physiol Renal Physiol 2011, 300:F488-F498

16. Gagliardini E, Benigni A: Therapeutic potential of TGF-beta inhibition in chronic renal failure. Expert Opin Biol Ther 2007, 7:293-304

17. Goumenos DS, Tsakas S, el Nahas AM, Alexandri S, Oldroyd S, Kalliakmani P, Vlachojannis JG: Transforming growth factor-beta(1) in the kidney and urine of patients with glomerular disease and proteinuria. Nephrol Dial Transplant 2002, 17:2145-2152

18. Hou CC, Wang W, Huang XR, Fu P, Chen TH, Sheikh-Hamad D, Lan HY: Ultrasound-microbubble-mediated gene transfer of inducible Smad7 blocks transforming growth factor-beta signaling and fibrosis in rat remnant kidney. Am J Pathol 2005, 166:761-771

19. Ka SM, Huang XR, Lan HY, Tsai PY, Yang SM, Shui HA, Chen A: Smad7 gene therapy ameliorates an autoimmune crescentic glomerulonephritis in mice. J Am Soc Nephrol 2007, 18:1777-1788

20. Kopp JB, Factor VM, Mozes M, Nagy P, Sanderson N, Bottinger EP, Klotman PE, Thorgeirsson SS: Transgenic mice with increased plasma levels of TGF-beta 1 develop progressive renal disease. Lab Invest 1996, 74:991-1003

21. Krag S, Osterby R, Chai Q, Nielsen CB, Hermans C, Wogensen L: TGF-beta1-induced glomerular disorder is associated with impaired concentrating ability mimicking primary glomerular disease with renal failure in man. Lab Invest 2000, 80:1855-1868

22. Sime PJ, Xing Z, Graham FL, Csaky KG, Gauldie J: Adenovectormediated gene transfer of active transforming growth factor-beta1 induces prolonged severe fibrosis in rat lung. J Clin Invest 1997, 100:768-776

23. Bonniaud P, Margetts PJ, Kolb M, Schroeder JA, Kapoun AM, Damm D, Murphy A, Chakravarty S, Dugar S, Higgins L, Protter AA, Gauldie $\mathrm{J}$ : Progressive transforming growth factor \{beta\}1-induced lung fibrosis is blocked by an orally active ALK5 kinase inhibitor. Am J Respir Crit Care Med 2005, 171:889-898

24. Mundel P, Reiser J, Zuniga Mejia BA, Pavenstadt H, Davidson GR, Kriz W, Zeller R: Rearrangements of the cytoskeleton and cell contacts induce process formation during differentiation of conditionally immortalized mouse podocyte cell lines. Exp Cell Res 1997, 236: 248-258

25. Faul C, Donnelly M, Merscher-Gomez S, Chang YH, Franz S, Delfgaauw J, Chang JM, Choi HY, Campbell KN, Kim K, Reiser J, Mundel $\mathrm{P}$ : The actin cytoskeleton of kidney podocytes is a direct target of the antiproteinuric effect of cyclosporine A. Nat Med 2008, 14:931-938

26. Gnudi L: Molecular mechanisms of proteinuria in diabetes. Biochem Soc Trans 2008, 36:946-949

27. Wolf G: Renal injury due to renin-angiotensin-aldosterone system activation of the transforming growth factor-beta pathway. Kidney Int 2006, 70:1914-1919

28. Ye X, Liu X, Li Z, Ray PE: Efficient gene transfer to rat renal glomeruli with recombinant adenoviral vectors. Hum Gene Ther 2001, 12:141148

29. Heikkila P, Tibell A, Morita T, Chen Y, Wu G, Sado Y, Ninomiya $Y$, Pettersson E, Tryggvason K: Adenovirus-mediated transfer of type IV collagen alpha5 chain cDNA into swine kidney in vivo: deposition of 
the protein into the glomerular basement membrane. Gene Ther 2001, 8:882-890

30. Ledbetter S, Kurtzberg L, Doyle S, Pratt BM: Renal fibrosis in mice treated with human recombinant transforming growth factor-beta2. Kidney Int 2000, 58:2367-2376

31. Mozes MM, Bottinger EP, Jacot TA, Kopp JB: Renal expression of fibrotic matrix proteins and of transforming growth factor-beta (TGFbeta) isoforms in TGF-beta transgenic mice. J Am Soc Nephrol 1999, 10:271-280

32. Wogensen L, Nielsen CB, Hjorth P, Rasmussen LM, Nielsen AH, Gross K, Sarvetnick N, Ledet T: Under control of the Ren-1c promoter, locally produced transforming growth factor-beta1 induces accumulation of glomerular extracellular matrix in transgenic mice. Diabetes 1999, 48:182-192

33. Clouthier DE, Comerford SA, Hammer RE: Hepatic fibrosis, glomerulosclerosis, and a lipodystrophy-like syndrome in PEPCK-TGF-beta1 transgenic mice. J Clin Invest 1997, 100:2697-2713

34. Isaka Y, Fujiwara Y, Ueda N, Kaneda Y, Kamada T, Imai E: Glomerulosclerosis induced by in vivo transfection of transforming growth factor-beta or platelet-derived growth factor gene into the rat kidney. J Clin Invest 1993, 92:2597-2601

35. Menini S, lacobini C, Oddi G, Ricci C, Simonelli P, Fallucca S, Grattarola M, Pugliese F, Pesce C, Pugliese G: Increased glomerular cell (podocyte) apoptosis in rats with streptozotocin-induced diabetes mellitus: role in the development of diabetic glomerular disease. Diabetologia 2007, 50:2591-2599

36. Matsui I, Ito T, Kurihara H, Imai E, Ogihara T, Hori M: Snail, a transcriptional regulator, represses nephrin expression in glomerular epithelial cells of nephrotic rats. Lab Invest 2007, 87:273-283

37. Yamaguchi Y, Iwano M, Suzuki D, Nakatani K, Kimura K, Harada K, Kubo A, Akai Y, Toyoda M, Kanauchi M, Neilson EG, Saito Y: Epithelial-mesenchymal transition as a potential explanation for podocyte depletion in diabetic nephropathy. Am J Kidney Dis 2009, 54:653664

38. Hirakawa M, Tsuruya K, Yotsueda H, Tokumoto M, Ikeda H, Katafuch R, Fujimi S, Hirakata H, lida M: Expression of synaptopodin and GLEPP1 as markers of steroid responsiveness in primary focal segmental glomerulosclerosis. Life Sci 2006, 79:757-763

39. Abbate M, Zoja C, Morigi M, Rottoli D, Angioletti S, Tomasoni S, Zanchi C, Longaretti L, Donadelli R, Remuzzi G: Transforming growth factor-beta1 is up-regulated by podocytes in response to excess intraglomerular passage of proteins: a central pathway in progressive glomerulosclerosis. Am J Pathol 2002, 161:2179-2193

40. Lai KN, Leung JC, Chan LY, Saleem MA, Mathieson PW, Tam KY Xiao J, Lai FM, Tang SC: Podocyte injury induced by mesangialderived cytokines in IgA nephropathy. Nephrol Dial Transplant 2009, 24:62-72

41. De Petris L, Hruska KA, Chiechio S, Liapis H: Bone morphogenetic protein-7 delays podocyte injury due to high glucose. Nephrol Dial Transplant 2007, 22:3442-3450

42. Mundel P, Reiser J: Proteinuria: an enzymatic disease of the podocyte? Kidney Int 2010, 77:571-580
43. Sever S, Altintas MM, Nankoe SR, Moller CC, Ko D, Wei C, Henderson J, del Re EC, Hsing L, Erickson A, Cohen CD, Kretzler M, Kerjaschki D, Rudensky A, Nikolic B, Reiser J: Proteolytic processing of dynamin by cytoplasmic cathepsin $L$ is a mechanism for proteinuric kidney disease. J Clin Invest 2007, 117:2095-2104

44. Yaddanapudi S, Altintas MM, Kistler AD, Fernandez I, Moller CC, Wei C, Peev V, Flesche JB, Forst AL, Li J, Patrakka J, Xiao Z, Grahammer F, Schiffer M, Lohmuller T, Reinheckel T, Gu C, Huber TB, Ju W, Bitzer M, Rastaldi MP, Ruiz P, Tryggvason K, Shaw AS, Faul C, Sever S, Reiser J: CD2AP in mouse and human podocytes controls a proteoIytic program that regulates cytoskeletal structure and cellular survival. J Clin Invest 2011, 121:3965-3980

45. Camici M: Urinary detection of podocyte injury. Biomed Pharmacother 2007, 61:245-249

46. Nakatsue T, Koike H, Han GD, Suzuki K, Miyauchi N, Yuan H, Salant DJ, Gejyo F, Shimizu F, Kawachi H: Nephrin and podocin dissociate at the onset of proteinuria in experimental membranous nephropathy. Kidney Int 2005, 67:2239-2253

47. Papapetropoulos A, Fulton D, Mahboubi K, Kalb RG, O'Connor DS, Li F, Altieri DC, Sessa WC: Angiopoietin-1 inhibits endothelial cell apoptosis via the Akt/survivin pathway. J Biol Chem 2000, 275:9102-9105

48. Maisonpierre PC, Suri C, Jones PF, Bartunkova S, Wiegand SJ, Radziejewski C, Compton D, McClain J, Aldrich TH, Papadopoulos N, Daly TJ, Davis S, Sato TN, Yancopoulos GD: Angiopoietin-2, a natural antagonist for Tie2 that disrupts in vivo angiogenesis. Science 1997 277:55-60

49. Woolf AS: Angiopoietins: vascular growth factors looking for roles in glomeruli. Curr Opin Nephrol Hypertens 2010, 19:20-25

50. Lee S, Kim W, Moon SO, Sung MJ, Kim DH, Kang KP, Jang KY, Lee SY, Park BH, Koh GY, Park SK: Renoprotective effect of COMPangiopoietin-1 in db/db mice with type 2 diabetes. Nephrol Dial Transplant 2007, 22:396-408

51. Kümpers P, David S, Haubitz M, Hellpap J, Horn R, Bröcker V, Schiffer M, Haller H, Witte T: The Tie2 receptor antagonist angiopoietin 2 facilitates vascular inflammation in systemic lupus erythematosus. Ann Rheum Dis 2009, 68:1638-1643

52. Campean V, Karpe B, Haas C, Atalla A, Peters $H$, Rupprecht $H$, Liebner S, Acker T, Plate K, Amann K: Angiopoietin 1 and 2 gene and protein expression is differentially regulated in acute anti-Thy $1.1 \mathrm{glo}$ merulonephritis. Am J Physiol Renal Physiol 2008, 294:F1174-F1184

53. Yuan HT, Khankin EV, Karumanchi SA, Parikh SM: Angiopoietin 2 is a partial agonist/antagonist of Tie2 signaling in the endothelium. Mol Cell Biol 2009, 29:2011-2022

54. Daly C, Pasnikowski E, Burova E, Wong V, Aldrich TH, Griffiths J, loffe E, Daly TJ, Fandl JP, Papadopoulos N, McDonald DM, Thurston G, Yancopoulos GD, Rudge JS: Angiopoietin-2 functions as an autocrine protective factor in stressed endothelial cells. Proc Natl Acad Sci U S A 2006, 103:15491-15496

55. Ward NL, Putoczki T, Mearow K, Ivanco TL, Dumont DJ: Vascularspecific growth factor angiopoietin 1 is involved in the organization of neuronal processes. J Comp Neurol 2005, 482:244-256 